\title{
Ovarian tumors in childhood and adolescents - Our eight years experiences
}

\author{
Archana Amatya, Ashma Rana, Geeta Gurung \\ Dept Ob/Gyn TUTH
}

\begin{abstract}
Aims: To study the distribution of different types of ovarian tumors seen in adolescents and children and evaluate the commonest tumor during this period.

Methods: A prospective study conducted at Dept of Ob/Gyn, Tribhuvan University Teaching Hospital form January 1999 - January 2008.

Results: There were a total of 80 cases of ovarian tumors in childhood and adolescents. Most of the cases had presented to the outpatient department of Ob/Gyn (54\%), Medicine (10\%), Surgery (21\%) and Emergency Unit (15\%). Majority of the cases were between the ages of 15 to 19 and tumors in childhood age up to 14 represented $21 \%$ of the total (<10year being 4 ). The most frequently occurring tumor was Germ cell tumors accounting for $59(73.7 \%)$ of the total. Out of which dermoid was the most frequently occurring in $45(76.2 \%)$. Nineteen $(23.71 \%)$ of the total tumor were malignant. All of them underwent laparatomy followed by enucleation (14); Unilateral ophoorectomy (28), unilateral salphingooophorectomy (36) and TAHBSO (2).

Conclusion: This study shows the preponderance of germ cell tumor and high percentages of malignancies within germ cell tumor in young children and adolescents.
\end{abstract}

Keyword: childhood, adolescent, ovarian tumors, malignancy

\section{Introduction}

Ovarian tumors are not a single entity but a complex wide spectrum of neoplasms involving a variety of histological tissues ranging from epithelial tissues, connective tissues or specialized hormone secreting germinal and embryonal cells ${ }^{1}$ Ovarian tumors are rare in childhood and the adolescents and are reported not to form more than $2 \%$ of all the cases seen. ${ }^{2}$ If present there is a $25 \%$ chance that the tumor is malignant. ${ }^{3}$ The symptoms are abdominal distension usually of short duration and the pain in the cases of torsion, rupture or malignancy. Unfortunately patients with ovarian tumors are often symtomless for a very long time and the signs are often non specific so by the time they are diagnosed, almost two thirds are far advanced with poor unfavorable prognosis. In childhood and adolescent's malignant tumors account for $7 \%$ of the total, which are usually dysgerminoma or malignant terratoma. ${ }^{3,4}$ We would like to share our experiences.

\section{Methods}

A prospective study of ovarian tumors falling in childhood and adolescent age group were collected and analyzed for their presenting symptoms, type of surgery, histopathogy and chemotherapy (adjuvant and neoadjuvant) or radiotherapy from Jan 1999 to Jan 2008 in the Department of Ob/Gyn. Datas entered in the performas were manually calculated.

\section{Results}

There were 80cases of ovarian tumor. Most of the patients presented to Ob/Gyn outpatient department although $21 \%$ were referred from Surgical OPD, $15 \%$

Correspondence

Archana Amatya, MD

Lecturer, Dept Ob/Gyn, Tribhuvan university teaching hospital, Katmandu, Nepal

Email:drarchu67@yahoo.com 
from emergency room and 10\% from Medical OPD. Majority of them were in between the age group of 15 to 19 (45) although there were 31 between 11 and 14 , and 4 in less than 10 years. Out of the 80,55 were unmarried and 15 married.

In the present study it was seen that pain was the most common feature, present in $62 \%$ the next common complaint was mass which was present in $45 \%$, followed by menstrual irregularities in $18 \%$, weight loss in $20 \%$ and torsion with acute abdomen in $6 \%$. However in the pediatric group mass and bleeding per vagina were the common symptoms.

The present study shows that the germ cell tumours $59(73.7 \%)$ were the most common of all the ovarian tumors followed by epithelial call tumors $18(22.58 \%)$. Of all the germ cell tumors $45(76.7 \%)$ presented as dermoid or mature cystic teratoma and $7(8.75 \%)$ were immature teratoma (Table 1) (Fig1,2 ). All the 80 cases underwent laparatomy.

Out of all the ovarian tumors $19(23.7 \%)$ were malignant which consisted of epithelial carcinoma 2[1 each of mucinous adenocarcinoma and clear cell carcinoma]; sex cord cell tumor i.e. granulosa cell tumor (3) and the rest were germ cell tumor 14[immature terratoma (7); endodermal sinus tumor (3), mixed germ cell tumors (2) and dysgerminoma (2) ( fig 3,4) ].
Malignancy was limited one ovary, stage 1a disease (11); bilateral ovarian involvement with stage $1 \mathrm{~b}$ disease met in (4) and stage 1c (2). Stage II (1) and one stage III (1). Treatment consisted of unilateral salphingo-oophorectomy (36); unilateral oophorectomy in (14); enucleation in 28 (out of which 3 had bilateral enucleation) and total abdominal hysterectomy in (2). Hysterectomy was done in cases of stage II and III diseases (Fig1). Out of the 19 malignant tumors 10 were lost to follow up. Following surgery almost all did well with an average duration of hospital stay being 4-8 days except in 4, among which 2 had wound infection and 2 had persisted vomiting prolonging the stay for 10 days. Chemotherapy was given to $8 / 9$ cases that came for follow up with histopathology.

In one case, no adjuvant therapy was required as the tumor fell in stage 1a, grade 1 .

Both the cases of dysgerminoma received 6 cycles of chemotherapy BEP (bleomycin, etoposde and cisplatin) regimen. Two cases of endodermal sinus tumor received 6 cycles of BEP as well but in the case of adenocarcinoma and 4 cases of immature teratoma each received 3 cycles of chemotherapy but did not continue later on.

Table I. Types of ovarian tumors in childhood and adolescents

\begin{tabular}{|c|c|c|c|c|c|}
\hline Type of tumor & & sub-types & Childhood & Adolescents & Total $n$ \\
\hline & Benign (16) & Serous & 2 & 6 & 8 \\
\hline & & Mucinous & 1 & 7 & 8 \\
\hline \multicolumn{6}{|l|}{ Epithelial (18) } \\
\hline & Malignant (2) & $\begin{array}{l}\text { Mucinous } \\
\text { adeno ca }\end{array}$ & 1 & - & 1 \\
\hline & & Clear cell & - & 1 & 1 \\
\hline Sex cord (3) & $\begin{array}{l}\text { Granulosa } \\
\text { stromal cell } \\
\text { tumors }\end{array}$ & - & - & 3 & 3 \\
\hline \multirow[t]{5}{*}{ Germ Cell (59) } & Benign 45 & Dermoid & 9 & 36 & 45 \\
\hline & Malignant 14 & $\begin{array}{l}\text { Immature } \\
\text { terratoma }\end{array}$ & 2 & 5 & 7 \\
\hline & & Mixed forms & - & 2 & 2 \\
\hline & & $\begin{array}{l}\text { Endodermal } \\
\text { sinus }\end{array}$ & 1 & 2 & 3 \\
\hline & & Dysgerminoma & 1 & 1 & 2 \\
\hline Total & & & 17 & 63 & 80 \\
\hline
\end{tabular}




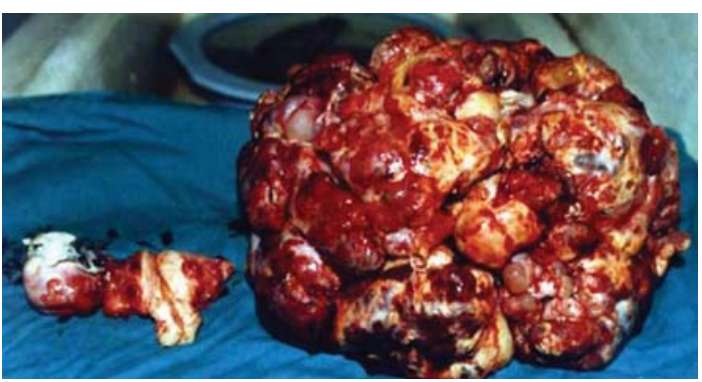

Fig I. Immature teratoma

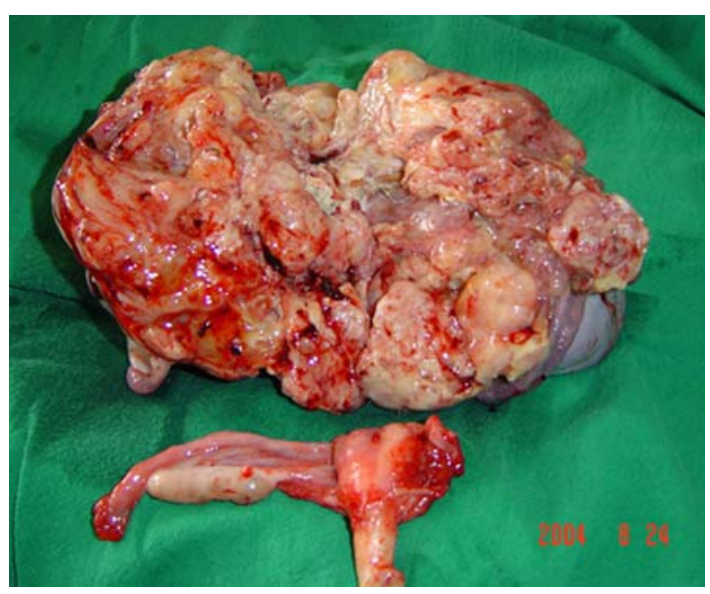

Fig 2. Immature teratoma

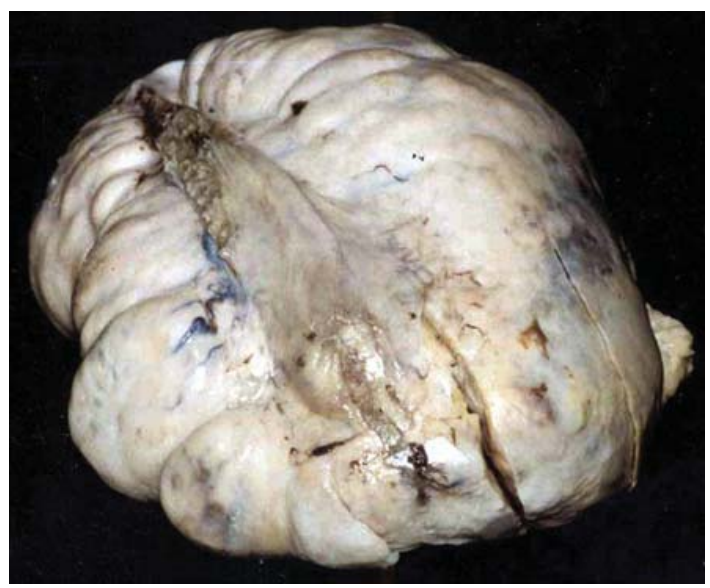

Fig 3. Dysgerminoma

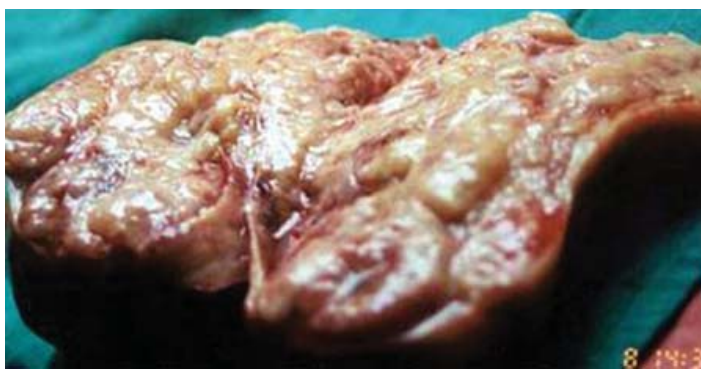

Fig 4. Dysgerminoma

\section{Discussion}

The ovary gives rise to a wider variety of tumors than any other organ in the body. Ovarian tumors are uncommon in children and frequently give rise to much clinical difficulty. ${ }^{1}$ Clinical presentation some what is different than the adults. Symptoms may not be associated with the lesion and sometimes ovarian enlargement may big enough so as to produce a pelvic swelling or tumor that can be felt in the abdomen in the prepubertal and pubertal age group. ${ }^{2}$ In the present study, pain was the most frequent symptom followed by mass and menstrual irregularities. In most cases the complaints of abdominal discomfort or distension leads to examination. In Lind fort's series pain was the main presenting complaint followed by abdominal distension and torsion. ${ }^{3}$ which was similar to our study where pain was the commonest symptom followed by mass abdomen, menstrual irregularities and weight loss. In a review of 81 cases from Lindfort, 17 tumors were benign teratomas, 13 malignant teratomas, 11 dysgerminomas and 8 granulosa cells tumors. ${ }^{4,5}$ The commonest is teratoma which is usually found in the form of dermoid.

In our study out of the 80 cases $19(23.7 \%)$ were malignant that is almost one fourth of all the ovarian tumors, out of which $5(6.25 \%)$ were in childhood and $14(117.5 \%)$ was in the adolescent age group, where as a study conducted by Beberic $\mathrm{B}$ et $\mathrm{al}{ }^{6}$ where the incidence was reported to be $10 \%$. Breen Maxson reported that one third of ovarian masses in children were cysts of existing follicles and two thirds were malignant. ${ }^{3}$ He described non neoplastic swellings were $36 \%$, the rest being new growths of one kind or the other. Huffman reported that $30 \%$ of 999 tumors and Breen and Maxson 355 of 1309 tumors in children and adolescents were malignant. ${ }^{2,5}$ In another series malignancy rates have varied from $15-35 \%$.

This study shows that there were a total 19(23.755) cases of malignancy which consisted of epithelial carcinoma 2[1 each of mucinous adenocarcinoma and clear cell carcinoma]; sex cord cell tumor i.e. granulosa cell tumor (3) and the rest were germ cell tumor 14[immature terratoma (7); endodermal sinus tumor (3), mixed germ cell tumors (2) and dysgerminoma (2)].

A different pattern of ovarian tumors are seen during childhood; in general the epithelial tumors are common in the adult, where as germ cell tumors and sex cord stroma tumors are preponderate in the younger age groups. ${ }^{2,3}$ Dysgerminoma account for $5-10 \%$ in the age group below 20. ${ }^{8}$ Malignant germ-cell tumors (GCT) account for $2.9 \%$ of all malignant tumors of children younger than 15 years of age. ${ }^{7,9}$ More than half of the tumors occur at extragonadal sites such as the ovaries 
(26\%), the coccygeal region (24\%), the testes (18\%) and the brain $(18 \%) .^{10,11}$

Our study shows that germ cell tumors (GCT) were the most common tumors seen in children and adolescents which accounted for $59(73.75 \%$ ) followed by epithelial tumors $18(22.5 \%)$ and sex cord stromal tumors were 3 . Interestingly Germ cell tumors were seen to be three times more than epithelial tumors in the younger age group.

Out of all the germ cell tumors malignancy was seen in $14(23.7 \%)$ where immature teratoma were the most common which comprised of $7(8.75 \%)$, followed by endodermal sinus tumor $3(5 \%)$ and mixed form and dysgerminoma $2(3.3 \%)$ which shows a high preponderance of malignancy in the adolescent and children within this group. Among the epithelial tumors malignancy was seen in $2(11.1 \%)$ which was seen as 1 each as mucinous adenocarcinoma and clear cell carcinoma. Amongst the sex cord stromal tumors there were 3 cases of granulosa cell tumors all occurring in the adolescent group.

Treatment is surgical, ovarian cystectomy being the preferred procedure exceptions in the case of malignant tumors. Ovarian conservation is the most important procedure. Cysts clearly benign should be removed by ovarian cystectomy not by ooophorectomy. ${ }^{7,8}$ A solid well defined tumor likely to be malignant should be dealt by ooophorectomy in the first instance, subsequent treatment must be considered in the light of the report of frozen section or later histology. All the cases in this study underwent laparatomy where 2 had to undergo total abdominal hysterectomy due to the extensive metastasis, 36 underwent unilateral salphingooophorectomy, 14 had unilateral oophorectomy, in 28 enucleation was possible where 3 had bilateral enucleation. Dysgerminoma are relatively radiosensitive and not of a high degree of malignancy, characteristics which suggest that unilateral removal is sufficient too, which was done in this study too followed by chemotherapy. ${ }^{6}$ Radiation therapy maybe given in cases of dysgerminoma and granulosa cell tumors when extension beyond the ovary has occurred.

Out of the 9 who came for follow up only 4 received the complete course of chemotherapy where as the other 5 were lost to follow up after the first three cycles which could be due to the fact that the patients kin did not understand the seriousness of the problem and the importance of follow up with consequent radiotherapy or chemotherapy or due to unavailability of resources. If conservative surgery is taken into account the child maybe left with a chance of fertility and if recurrence does occur later, radiotherapy could be employed.

\section{Conclusion}

This study shows the preponderance of germ cell tumor and high percentages malignancies within germ cell tumor in young children and adolescents.

\section{References}

1. D K Edmonds. Gynecological disorders of childhood and adolescents. In: Dewhursts Textbook of Obstetrics and Gynaecology for postgraduates. Sixth edition, London, Blackwell scientific publications 1986; 12-16

2. Breen JL, Maxson WS. Ovarian tumors in children and adolescents. Clin Obstet Gynecol. 1977 Sep; 20(3):607-23.

3. Linfors O. Am.chir. Gynaec. Fenn 60, Suppl 173, 1971

4. Carlson JA. Gynecological neoplasms. Pediatric and adolescents obstetric and gynaecology, New York, Springer Verlag. 1999, pg 124

5. Huffman JW. The Gynaecolgy of children and adolescents. Philadelphia,Sanders 1968

6. Beric B, Gebauer, Dordevic M. Malignant. Ovarian tumors in childhood and adolescents in Novi Sad. Jugosl Ginekol Perinatol 1991 May-Aug; 31(3-4):92-93

7. Ehren IM, Mahous GH. Isacs H. Benign and malignant ovarian tumors in children and adolescents. Am J Surg ; 147:339,

8. Van Winter, Simmon PS, Podrataz KC. Surgically treated adnexal masses in infancy, childhood and adolescents. Am J Obstet Gynecol 1998;170:1780

9. Yakushiji M, Matsukuma T, Abe M. Ovarian tumors in children and adolescents less than 20 year's age. Acta Obstet Gynecol Jpn 1981 Jun; 33(6):833-8

10. Freud E, Golinsky D, Steinberg RM. Ovarian masses in children, Clinical Paediatrics 1999; 1 38(1), 573-577

11. Göbel U, Calaminus G, Engert J, Kaatsch P, Gadner H, Bökkerink JP, Hass RJ, Waag K, Blohm ME, Dippert S, Teske C, Harms D. Teratomas in infancy and childhood. Med Pediatr Oncol 1998 Jul; 31(1):8-15. 